\title{
GIS-Based Allocation of Lignocellulosic Biomass in Biorefineries and Depots
}

\author{
Daniela S. Gonzales, Stephen W. Searcy ${ }^{*}$ \\ Department of Biological and Agricultural Engineering, Texas A\&M University, TAMU 2117, College \\ Station, TX 77843-3131, USA
}

\begin{abstract}
While sufficient biomass has been identified to meet the Renewable Fuel Standard (RFS2) ${ }^{1}$ targets by previous studies, availability does not equal access. Our objective was to quantify the potential accessible and stranded herbaceous biomass from different scenarios of predicted available biomass in both Texas and the US. The location and size of potential biorefineries and depots was determined using the geographic location of suitable lands for biomass, the transportation infrastructure and published economic constraints for minimum biomass supplied to a facility within a specified neighborhood. Our GIS-based heuristic addresses the capacitated facility location problem by distributing potential biomass along a county's suitable lands. Road and rail proximity optionally was included in the algorithm. The total stranded biomass in Texas was $28 \%$ of the total available biomass. Including the constraint of the transportation network accessibility (rail and appropriate roads) when determining facility location increased the total stranded biomass to $33 \%$. Using county centroids as supply points and potential facilities led to an increase of $7 \%$ in total biomass captured by all facilities in Texas when compared to our raster-based heuristic. The nationwide accessible biomass is $90 \%$ of the available biomass, $78 \%$ of which is captured by biorefineries. In total, 77 biorefineries and 171 depots were identified in the US, which projects to 184 million $\mathrm{Mg}_{\text {year }}{ }^{-1}$ delivered to biorefineries and depots, or 65.3 billion liters of advanced biofuels, more than the targeted 60 billion liters of advanced cellulosic biofuel in the RFS2.
\end{abstract}

Keywords: Billion-Ton Study, biomass, perennial grasses, switchgrass, precipitation

*Corresponding author. Tel.: +1 979845 3940; Fax: +1 979450 3156; E-mail address: s-searcy @ tamu.edu (Stephen W. Searcy)

${ }^{1}$ Renewable Fuel Standard

(C) 2016. This manuscript version is made available under the Elsevier user license http://www.elsevier.com/open-access/userlicense/1.0/ 


\section{Introduction}

The Renewable Fuel Standard (RFS2) has set a targeted production of 57 billion liters (15 billion gallons) of conventional renewable transportation fuel (such as corn grain based fuel) and 79 billion liters (21 billion gallons) of advanced biofuels by 2022, of which at least 60 billion liters (16 billion gallons) must be some type of cellulosic biofuel. One of the most significant challenges to accomplishing the long term biofuel production goals is the ability to be price competitive against fossil fuels, particularly petroleum. Biomass feedstock logistics, which encompass activities such as harvesting, transporting, and preprocessing, collectively represent one of the greatest challenges to the success of the biofuel industry [1]. The feedstock supply chain (SCh) cost for the corn-based ethanol industry represent $8 \%$ of the total cost of ethanol production [2], as opposed to $35 \%$ to $65 \%$ of the total production costs $[1,3,4]$ for the cellulosic ethanol industry. Part of this big difference in production costs is that the corn-based ethanol industry is already established while the cellulosic ethanol industry is still an emerging industry. Logistical costs that exceed $25 \%$ of the total biomass value leave very little room for profit for biomass producers and biorefineries [2]. To reduce these costs, improvements to the entire value-chain from harvest through bio-reactor throat are required. A higher density feedstock with desirable flow characteristics is fundamental to optimize its collection and handling activities, reduce total energy use, and maximize the revenue of the industry [1].

Current pioneer biorefineries rely on local supplies of baled biomass with trucks as the primary transport mechanism. In this paper, such SCh is referred to as the conventional-bale system (CBS). The CBS for biofuels utilizes a decentralized distribution system with low biorefinery capacities and high transportation costs. Based on a studies by Aden et al. [5] and Riley and Schell [6], the Department of Energy’s (DOE) Office of the Biomass Program (OBP) considered biorefinery capacities of 2,000 dry $\mathrm{Mg}_{\text {(DMg) day }}{ }^{-1}$ to be approximately optimal for a CBS with an 81-km (50-mile) collection radius in a high-yield corn production area. While the weather conditions, water availability, cropping systems, transport load limits and other regulations in some regions in the US are capable of supporting a CBS, conditions in other areas of the US may not. Hence, a portion of the biomass resources in the US may not be accessible to the biomass industry 
with a CBS. The biomass resources located in these inaccessible areas are referred in this document as stranded biomass.

Biomass bulk density has a major impact on: storage, harvest and transportation costs; harvest and labor requirements; biorefinery capital cost; energy requirements; material handling; and processing complexity $[2,7]$. Truckloads of baled biomass typically are limited by volume rather than weight, resulting in higher delivery costs (transportation and handling) than necessary. To utilize potentially stranded biomass and improve the biomass logistic model, the DOE has proposed an advanced biomass feedstock SCh design that would modify the biomass using a uniform-format feedstock system (UFFS) [8]. This effort has primarily focused on preprocessing biomass at the point of harvest and/or preprocessing depot into a higher mass bulk density, aerobically stable, standardized, easily transportable, bulk solid or liquid commodity with characteristics similar to grains. Biomass diversity is envisioned to be managed at the preprocessing depot, which allows subsequent supply system infrastructure to be similar for all biomass resources. Similar studies also propose a network of depots as a way to address the transportation issues of this industry, refer to as "regional biomass preprocessing centers" [9]. The densified material in the UFFS, compared to raw biomass, is improved for longer-term storability, handling, and transport; in addition to being ready for efficient conversion. The UFFS targets dry matter bulk density of greater than $0.48 \mathrm{DMg} \mathrm{meter}^{-3}\left(30 \mathrm{lb} \mathrm{ft}^{-3}\right) \mathrm{after}$ preprocessing [8]. However, densification requires an unrecoverable energy investment, hence, energy reductions in other portions of the SCh must be obtained to achieve maximum net energy content and minimum total logistic cost. The underlying approach is that by densifying biomass early in the SCh, the transportation cost, energy invested on transportation and loss of biomass due to handling and storing will be reduced. Raw, unprocessed biomass (i.e. as collected from the land) is not in a format suitable for easy handling by high-capacity transportation modes (i.e. rail, barge).

The inclusion of preprocessing depots and the use of high-capacity transportation modes anticipates the expansion of the potential feedstock collection radius of a biorefinery, hence allowing for the development of biorefineries with higher nameplate capacity, reducing feedstock supply risk and introducing more resources into the biomass market. Biorefineries with higher capacities may take advantage of economies of 
scale and reduce the cost-per-unit of output. A change from the CBS to a UFFS may allow an expansion of feedstock availability for biorefineries and, consequently, offer investors the confidence of a sustainable supply. Consequently, farmers may be able to participate in the added-value process at the depots. The proposed model for the biomass industry has a similar concept to the one for co-operative elevators in the grain industry.

Any facility, regardless of size, will source the lowest cost feedstocks, which likely will be a combination of local delivery (bales) and longer distance delivery (higher density biomass). Figure 1 represents the structure of a SCh that would include biorefineries and depots, a combination of the CBS and the UFFS. The larger circles represent the $81-\mathrm{km}$ radius of biomass delivered from a harvesting site to a biorefinery in trucks. The preprocessing depots will provide additional market options for geographically stranded feedstocks that are not within an 81-km biorefinery radius, hence feedstocks that are not economically feasible to be collected in the CBS [10]. The smaller circles illustrate the 32-km (20 mile) collection radius of a depot. A densified version of biomass (module transport units, pellets or briquettes) would be delivered from depots to biorefineries. A depot may contribute to the closest biorefinery, but the uniform format would allow each depot to participate in a regional market (represented by dotted lines in Fig.1). Note that even with the inclusion of depots in the system, some biomass might remain stranded.

$<$ Fig. $1>$

In this study, our objective was to determine the structure of the likely biomass feedstock SCh that will develop in the US using herbaceous materials. While sufficient biomass has been identified to meet the RFS2 targets by previous studies [11, 12], availability does not equal access. We evaluated accessibility of herbaceous biomass using different scenarios of predicted biomass given the geographic location of suitable lands for biomass by using appropriate land use classifications from the 2011 National Land Cover Data (NLCD) [13], the transportation infrastructure and constraints based on the economics presented in the literature review for minimum biomass supplied to a facility within a specified neighborhood. Our aim was to locate 
economically viable biorefineries and depots, in addition to quantify potential accessible and stranded biomass. We assumed that technology will be available for a conversion facility capable of handling the different physical and chemical properties of all the potential types of biomass (crop residues and energy crops in baled or high density formats). This study was limited to herbaceous biomass, and all references to biomass production are ignoring other sources.

\section{Literature Review}

Reliable inventories of biomass are important for an accurate study of the expansion of the biofuels industry in the US. The DOE published a strategic analysis that estimates the US agriculture and forest resources have the capability to produce at least 907 million DMg (one billion dry tons) of biomass annually, in a sustainable manner [11]. The Billion Ton Study (BT2) provides a means to predict the development of the biofuels industry. Gonzales et al. [12] concluded that BT2 estimates of perennial grass were overestimated, by $8 \%$ and $87 \%$ in the US and Texas respectively, for counties with low average precipitation along the 100th Meridian. These assessed geospatial inventories of cellulosic feedstock paved the way to focus on the logistics of agricultural feedstocks for liquid fuel production.

Traditionally, the literature expresses biomass quantities in either dry short US tons ( 1 short US ton = $0.907 \mathrm{Mg})[11,14]$ or in dry metric tons - also referred to as tonnes $-(1$ metric ton $=1 \mathrm{Mg})[5,15]$. Some research papers are not explicit on what unit (short US tons or metric tons) was used in their studies, which brings some confusion to the readers. In addition, there is a lack of consistency within the literature in the use of DMT as an acronym. Some studies use DMT to express dry matter tonnes [16, 17] or dry metric tons [18]. Reports from the Idaho National Laboratory (INL) use DMT to express dry matter tons [19, 20]. The lack of unit consistency brings confusion, thus, in this study we used DMg (dry mega grams) as the unit of mass for biomass.

A biorefinery size will have a significant influence on the biofuel production cost. Determining the optimal size for a biorefinery includes recognizing the tradeoffs between economies of scale with larger 
conversion plants and higher feedstock delivery costs and has been of continuous debate in the literature. Two National Renewable Energy Laboratory (NREL) studies on biochemical conversion of corn stover indicated that 2,000 DMg day ${ }^{-1}$ is approximately optimal for a CBS with an 81-km collection radius in a high-yield corn production area [5, 6]. A different study of the tradeoffs between scale economies and transportation costs through a mathematical model revealed that the estimated net present value of lignocellulosic biomass plants (energy crops, crops and wood residues) is maximized at a capacity of 3,955 $\mathrm{DMg} \mathrm{day}^{-1}$ [21]. Conversely, Wright \& Brown [22] calculated that the optimal size for a biochemical cellulosic ethanol plant was 4,281,912 DMg. Assuming Wright \& Brown estimated a total of 350 working days year ${ }^{-1}$, the daily plant capacity presented was of $12,232 \mathrm{DMg}$. A later study reported the optimal plant size to be $3,450 \mathrm{DMg}^{-1 a y}{ }^{-1}$ [23] when using a transportation winding factor for feedstock delivery to the plant. They claimed that the big difference in their results compared to Wright \& Brown [22] is because the previous authors used lower hauling costs and ignored storage costs.

Aden et al. [5] implied that if higher quantities of biomass become available, increasing the plant size from 2,000 to $10,000 \mathrm{DMg} \mathrm{day}^{-1}$ decreases the non-feedstock costs by $\$ 0.05 /$ liter $\left(\$ 0.19\right.$ gallons $\left.^{-1}\right)$ or about $25 \%$. But, the increased cost of feedstock to supply the higher-capacity plant, eliminates $\$ 0.034 /$ liter of these savings. And, that a plant capacity of $6,000-8,000 \mathrm{DMg}$ day $^{-1}$ will achieve the net savings of $\$ 0.016$ with no additional cost savings realized above that size. Similarly, Hamelinck et al. [3], analyzed the economics of biorefinery capacities at 2,000, 5,000 and 10,000 DMg day ${ }^{-1}$ and declared that the development of a conversion plant with a capacity higher than $10,000 \mathrm{DMg} \mathrm{day}^{-1}$ of lignocellulosic biomass is less evident to be realized. Carolan et al. [9] concluded that future large biorefineries will have capacities of 4,536-9,072 DMg day $^{-1}\left(5,000-10,000\right.$ tons day $\left.{ }^{-1}\right)$ of biomass to achieve process economies, if not larger. Later studies specified that under a system that includes pre-processing depots, cost advantages can be achieved with larger biorefineries above 5,000 $\mathrm{DMg}_{\text {day }}{ }^{-1}$ and up to $10,000 \mathrm{DMg}_{\text {day }}{ }^{-1}[10,24,25]$. The Bioenergy Technologies Office's Multi-Year Program Plan of March 2015 has set a cost target of fuel production at $\$ 0.79$ per liter (\$3 per gallon) of Gasoline Equivalent (GGE) with plant capacities of 2,000 DMg feedstock day ${ }^{-1}$ by 2022 [26]. 
Because the idea of a pre-processing depot as an additional echelon to the agricultural feedstock for liquid fuels SCh is relatively new, further research is necessary to estimate an optimal depot size and supply radius. Argo et al. [10] indicated that the size of a depot is based on the throughput capacity of the grinder, which is the most capital-intensive equipment required at the facility. Lamers et al. [15] assumed that depots are modular and can be incrementally scaled in a stepwise fashion of $9 \mathrm{Mg}$ hour $^{-1}$ and adopted a maximum depot capacity of $9.07 \mathrm{Mg}$ hour $^{-1}$ in their analysis - note that the capacity of the grinder for the high moisture pelleting process is of $4.5 \mathrm{Mg}$ hour $^{-1}$. Assuming 350 labor days and 3 shifts per day at the depot, the yearly capacity would be $76,188 \mathrm{Mg}$ year $^{-1}$.

Locating a facility and determining the nameplate capacity of the facility is the most crucial decision to realize an efficient SCh due to the high investment costs and availability of feedstock $[27,28]$. The facility location problem (FLP) in general networks is known as a non-deterministic polynomial-time hard (NP-hard) problem to solve for optimality. The NP-hard classification for decision problems refers to the difficulty to solve the problem. If the algorithm to solve a problem can be translated into one for solving any other NPproblem, a problem is said to be NP-hard. In other words, an NP-hard problem is at least as hard as any NPproblem, but it might be harder [29]. An NP-problem permits a nondeterministic solution and the number of steps needed to verify the solution is bounded by some power of the problem's size [30]. Consequently, the use of exact solution methods is limited by the size of the problem. Many studies have approached the facility location problem, as well as the capacitated FLP (CFLP) through heuristics such as the local search algorithm, linear-programming rounding, dual-based ascent, lagrangian relaxation, greedy algorithms and greedy augmentation [31-41]. Acharya et al. [27] presented a decision support system that could be used by managers to solve the SCh problems of capacity and location for a single new or multiple new biorefineries. They addressed four SCh problems: the transportation problem (when location and capacity is known), the capacity allocation and transportation problem (when location is known but the capacity is unknown), the facility location problem (when capacity is known and location is unknown), and the capacitated facility location problem (when capacity and location is unknown). The model was validated with biomass data for Mississippi at the county level obtained from the National Agricultural Statistic Service (NASS). County centroids were identified as potential locations for facilities and biomass supply points. 
The rather dispersed distribution of biomass has caused researchers to use spatial analysis to understand the geographic context of bioenergy supplies and analyze the potential for the biofuel industry. A Geographic Information System (GIS) has the capabilities of storing, evaluating, and displaying multiple layers of geospatial data effectively [42]. GIS includes digital maps that are linked to tables of attributes. These attributes can be the amount of switchgrass available or the average annual precipitation in a county. Software packages such as the ESRI ArcMap enabled the analysis and manipulation of geospatial data. Several researchers have used GIS as a decision support system to evaluate the facility location problem for plants fed by agricultural products $[43,44]$. At the University of Hawaii, researchers linked geospatial data for roads, soil and land-use with forest productivity and economic models to assess the delivery cost of eucalyptus wood to potential conversion facilities on the Hawaiian Islands [45-47]. Graham et al. used raster data to locate biorefineries based on the yield and distance to cropland [44]. Each pixel was a potential biorefinery. A sequential method was used to locate the facilities. Once a facility was located, the croplands that would supply the plant were removed from further consideration to allocate the next facility. Panichelli \& Gnansounou applied a least-cost approach to locate various bioenergy facilities (of a fixed capacity) simultaneously based on the significant variability of farmgate prices [48]. Most of the literature assumes that available feedstock for a county is in the centroid [27, 49, 50] or in county seats [15].

A more spatially accurate means of allocating feedstock would be to utilize datasets such as the NLCD [11] to distribute the biomass within a county on the basis of known land use. The most recent public inventory of available biomass in the US is the BT2, hence, the BT2 is a better resource to determine the structure and development of the biofuels industry than data from NASS. While previous work has been highly variable in the estimation of an optimum biochemical refinery capacity, a value between 2,000 and $10,000 \mathrm{DMg} \mathrm{day}^{-1}$ was most commonly suggested. Thermochemical and pyrolysis facilities may have different optimal sizes. The literature on optimal depot size is limited but it approximates a capacity of 76,188 $\mathrm{Mg}$ year $^{-1}$, as suggested by Lamers et al. [14].

\section{Datasets and Methodology}


In this paper we developed the potential structure of the biofuels industry using the best available information in the literature. We developed a GIS-based heuristic that addresses the capacitated facility location problem based on a maximization of access to biomass resources within a specified neighborhood radius and a minimum of total biomass available to be supplied to a facility. We chose a raster approach as opposed to a network approach given that the former allows for continuous resource surfaces. The algorithm consists of distributing potential biomass along the suitable lands of each county (based on the 2011 NLCD), as opposed to assuming that all the biomass is located in a county centroid.

We used the herbaceous biomass inventories in the baseline scenario presented in the BT2 and the revised inventories under scenarios past100 and al125 from a previous study by Gonzales et al. [12]. In short, the past100 scenario has the same land use assumptions for perennial grasses as the BT2, but the biomass inventory quantities predicted are different due to improvements to the simulation model used in both studies (Policy Analysis System -POLYSYS) between 2011 and 2015. The all25 scenario used the average annual precipitation county boundaries to restrict all conversion from pastureland and/or cropland to perennial grasses. (The reader is referred to Gonzales et al. [12] for a deeper understanding of the land use change assumptions used in the past100 and all25 scenarios.)

Total herbaceous biomass predicted in the BT2 at the $\$ 66.14 \mathrm{Mg}^{-1}$ farmgate price (208 million DMg year $^{-1}$ ) slightly increased under the past100 scenario (209 million DMg year $\left.{ }^{-1}\right)$ and decreased under the all25 scenario (205 million DMg year ${ }^{-1}$ ). Even though the inventories were approximately the same in the BT2 and in the study by Gonzales et al, the biomass geographical location changed across the nation. For example, Texas herbaceous biomass inventories were 16.4, 6.48 and 4.12 million DMg year ${ }^{-1}$ respectively under the BT2, past100 and all25 scenarios at the $\$ 66.14 \mathrm{Mg}^{-1}$ farmgate price. The values in past100 and all25 scenarios at the $\$ 66.14 \mathrm{Mg}^{-1}$ farmgate price were closer to the BT2 scenario at the $\$ 55.12 \mathrm{Mg}^{-1}$ farmgate price (8.53 million DMg year $\left.{ }^{-1}\right)$. Hence, in this study we used biomass inventory estimates at the $\$ 55.12 \mathrm{Mg}^{-1}$ farmgate price from the BT2 scenario and at the $\$ 66.14 \mathrm{Mg}^{-1}$ farmgate price from the revised inventories by Gonzales et al. [12]. 
As per the BT2 assumptions, annual energy crops may be grown on croplands as part of a crop rotation, and perennial grasses may be established on cropland or pastureland [11, 12]. Hence, lands classified as cultivated crops in the 2011 NLCD were identified as suitable lands for annual energy crops and crop residues such as barley straw, corn stover, oats straw, sorghum stubble and wheat straw and a portion of the estimated perennial grasses. Lands classified as grassland/herbaceous and hay/pasture in the 2011 NLCD were identified as suitable lands for the other portion of perennial grasses, estimated to be grown on pastureland in the BT2. For simplicity, we referred to grassland/herbaceous and hay/pasture lands from the NLCD as pastureland, and cultivated crops as cropland. Table 1 illustrates these assumptions.

$<$ Table $1>$

To allocate the county-based quantities of potential biomass in the NLCD raster data, we first extracted the suitable areas in two different raster files, the cropland and pastureland. The resulting raster files are presented in Figure 2. Note that lands such as wetlands, aquaculture, open water, developed areas, barren and forest were removed from the NLCD layer. In each map, the $100^{\text {th }}$ meridian and the $28^{\text {th }}$ parallel are shown. These were limits to perennial grass production used in the BT2 study. The biomass production attribute value assigned to the pixels representing suitable lands was the total available herbaceous biomass available in a county divided by the total suitable area of that land type (cropland and pastureland) in the county (found using the ArcMap Zonal Statistics tool).

$<$ Fig. $2>$

For example, in scenario all25 the total available herbaceous biomass that is projected to be grown on cropland in Parmer County, TX was estimated at 242,337 DMg (of which 56\% is corn stover, $39 \%$ is wheat and 5\% is sorghum). Given that the average corn, sorghum and wheat yields in the Parmer County are 913.5, 414.7 and 223.9 $\mathrm{DMg} \mathrm{km}^{-2}$ [52] the weighted average herbaceous biomass yield for cropland in Parmer County under this scenario should be $620 \mathrm{DMg} \mathrm{km}^{-2}$. Since the total cropland in Parmer County in the 2011 NLCD raster was $1,645 \mathrm{~km}^{2}$, each $2.59 \mathrm{~km}^{2}\left(1 \mathrm{mile}^{2}\right)$ pixel that represents the location of cropland in the raster was given a value of $148 \mathrm{DMg}$ in our study to represent the herbaceous biomass yield. In other words, 
we distributed available biomass evenly throughout suitable areas (cropland in the example) in Parmer County.

While we acknowledge that our methodology uses a lower than actual $\mathrm{DMg} \mathrm{km}^{-2}$ yield, we believe that the raster approach used here is an improvement over assuming that all the biomass is in the centroid of a county, since the latter implies that the centroid has a very high yield. If we assumed that the centroid is a 2.59 $\mathrm{km}^{2}$ pixel, then the yield at the centroid of Parmer County would be of $93,566 \mathrm{DMg} \mathrm{km}^{-2}(242,337 \mathrm{DMg}$ divided by $2.59 \mathrm{~km}^{2}$ ) and the yield everywhere else in the county would be zero. Conversely, a different approach would be that for a given county, the yield is the total biomass available over the total area of the county. With this method, every $2.59 \mathrm{~km}^{2}$ pixel in Parmer County would have a value of $147 \mathrm{DMg} \mathrm{km}{ }^{-2}$ (242,337 DMg divided by $2,292 \mathrm{~km}^{2}$ ), regardless of whether the location of the pixel is in a suitable land for herbaceous biomass or not. In fact, the county yields for herbaceous biomass found in our study represent a lower bound to estimate the actual yields. The yield values could be refined using the Cropland Data Layer (CDL) [53], which provides geo-references for specific crops. For this study, we used the NLCD instead of the CDL since the latter adds additional complexity (time and memory resources).

Map algebra, a tool available in ArcMap, was used to overlap the two different raster files presented in Figure 2 (cropland and pastureland) into a new raster referred to as the biomass raster. In the biomass raster any one pixel in either of the raster files will have a value of zero (other land use classification), a value of biomass yield from cropland or a value of biomass yield from pastureland. We acquired a rounding error of $1 \%$ when converting the data from the database to pixel values in the raster files.

The GIS-based heuristic was run to locate and size the biorefineries and depots that will likely develop in the state of Texas by 2022 given the BT2, past100 and all 25 scenarios for potential biomass. The contiguous US was evaluated using the results of the all25 scenario. We assumed any biorefinery has the capabilities to handle feedstock in the form of bales (delivered from farms) and densified biomass (delivered from depots). We assumed that a biorefinery needs at least 2,000 DMg day ${ }^{-1}$ (or 700,000 $\mathrm{DMg}_{\text {year }}{ }^{-1}$ with 350 working days in a year) to operate. Additionally, we constrained the supplied radius for a conversion plant to 
81-km radius. Baled biomass will arrive at depots (from farms), where it will be densified. We used $240 \mathrm{DMg}$ $\mathrm{day}^{-1}$ as the minimum depot size. Additionally, we constrained the supplied radius for a depot facility to 32 $\mathrm{km}$ (20-mile). The supply radius for the depots used aligns with the conceptual UFFS design envisioned by INL [8].

To evaluate the distribution of the biomass and locate facilities, we used the focal statistics tool form ESRI ArcMap. This tool calculates, for each input pixel, a statistic of the values within a specified neighborhood around it. The input to this tool was the biomass raster, the statistic calculated was a summation with a neighborhood of $81-\mathrm{km}$. The pixel values on the output raster from the focal statistics tool, referred to as the biomass cumulative raster, was the sum of available biomass within the pixel's $81-\mathrm{km}$ neighborhood.

Like the method by R. L. Graham et al. [44], we considered every pixel in the biomass cumulative raster as a potential biorefinery and used a sequential method to locate the facilities. The pixel in the biomass cumulative raster with the highest value will have the most biomass within its surroundings and hence, it was chosen as the first biorefinery location with a nameplate capacity of that pixel value. Before the next biorefinery location was chosen, the pixel values chosen to supply the biorefinery found are changed to zero in the biomass raster with the extract by circle tool in ArcMap. The new biomass raster was used again as an input to the focal statistics tool in order to find the next biorefinery. This process was repeated until the pixel with the highest value in the biomass cumulative raster (output of the focal statistics) was less than $2,000 \mathrm{DMg}$ day $^{-1}$. Assuming a generalized conversion rate of 355 liters $\mathrm{DMg}^{-1}$ (85 gallons dry ton $\left.{ }^{-1}\right)$ [54], the smallest facility will produce 248.5 million liters year ${ }^{-1}$. The value of pixels that are not assigned to any biorefinery represent stranded biomass.

Figure 3 illustrates how the raster-based heuristic used in this study locates facilities (biorefinery in this case) based on a maximization of available biomass within the supply/market radius. In the figure, the colored pixels/squares represent the herbaceous biomass yields for each county under the all25 scenario. The biorefinery found in the picture was located in Castro County and the market radius of this facility expands to Deaf Smith, Randall, Armstrong, Parmer, Swisher, Briscoe, Bailey, Lamb, Hale and Floyd County. Note that suitable lands in Briscoe County are concentrated in the south and west of the county and about $40 \%$ of the 
county's biomass lies inside Castro's biorefinery market radius. If we were to assume that the biomass in Briscoe County is located at the county centroid (as done in previous studies), none of this biomass would be considered within the Castro's biorefinery market.

\section{< Fig. $3>$}

To analyze the impact of the proximity to the existing Texas transportation network (roads and rails), we extended our study to include a constraint to the algorithm that ensures that a biorefinery may not be located further than $1.62 \mathrm{~km}$ from both transportation networks, road and rail. The $1.62 \mathrm{~km}$ distance is chosen considering the footprint of the biorefinery facility and the additional storage space for processed and unprocessed feedstock. In addition, this distance was consistent with the size of the National Land Cover Database raster used in this study. The road and railroad data layers were obtained from the Texas Natural Resources Information System (TNRIS) website [55]. The roadway raster, as defined by TNRIS, is a comprehensive routed GIS centerline base map for the state of Texas. The roads chosen as suitable for this study are U.S. numbered highways, state highways, farm-to-market roads and all other roads considered to be in the highway system by the Texas Department of Transportation, excluding interstate highways. A biorefinery will not be sited on heavily trafficked roads. Thus, the polylines classified as interstate highways in the roadway dataset were removed from the analysis. The Pseudo-code presented in Figure 4 represent the algorithm used to solve the facility location problem. Note that the intersection line in the pseudo-code (in grey text) will only be included in runs with the rail and road transportation proximity as an additional bound to locate facilities. In addition, the variables in the pseudo-code: Biomass $_{(\mathrm{x})}$, BiomassCumulative $_{(\mathrm{x})}$, Road and Rail are raster files that represent the amount of biomass in each pixel, the amount of biomass in the neighborhood of each pixel, and pixels that represent the location of roads and rails respectively. The biorefinery $(\mathrm{x})$ variable is a set of the biorefineries found.

< Fig. 4 >

To determine the accessible herbaceous biomass from the total available biomass in TX, we identified potential locations and capacities of biorefineries and depots under different scenarios of predicted biomass (baseline scenario in the BT2, past100 and al125). In addition, we evaluated the incorporation of the 
transportation network in the heuristic under the all25 scenario for the state of Texas. Using the same biomass predictions, we compared our raster-based heuristic with the conventional method of using county centroids as supply points and potential facilities. Finally, we expanded our study to the whole nation using the past100 and all25 scenarios of predicted biomass.

\section{Results and Discussion}

Table 2 presents the potential biorefineries and depots with a feedstock supply potential of at least 2,000 DMg day ${ }^{-1}$ and $240 \mathrm{DMg}_{\text {day }}{ }^{-1}$ respectively, the total estimated accessible biomass in Texas, and the total probable stranded biomass for each of the POLYSYS assumptions. Stranded biomass was calculated by subtracting the biomass that could be accessed by biorefineries and depots from the total potential biomass in the state for a given scenario. We found that $18 \%, 21 \%$ and $28 \%$ of the total available biomass was found to be stranded under each of the scenarios studied in this paper, BT2, past100 and all25 respectively. Figure 5 illustrates the geographic location of biorefineries and depots found under each production level assumption as well as the market region that is predicted to supply each facility in this study.

$<$ Table $2>$

$<$ Fig. $5>$

To analyze the impact of the proximity to the existing Texas transportation network, we incorporated the rail and road transportation proximity as a bound to locate facilities under the all 25 scenario in Texas. The additional constraint, which ensures that a biorefinery may not be located further than $1.62 \mathrm{~km}$ from both network (roads and rails), resulted in a decrease of $7 \%$ of the total accessible biomass in the system that includes both biorefineries and depots. Consequently, the transportation constraint increases the total stranded biomass under the all25 scenario from $28 \%$ to $33 \%$ (Table 3). Note that there was no depot found in Kendall County with the additional transportation bound since Kendall County does not have rail service.

$<$ Table $3>$ 
To evaluate the effect of the $2,000 \mathrm{DMg}_{\text {day }}{ }^{-1}$ capacity assumption for biorefineries under the all25 scenario, we relaxed the capacity constraint to a value of $1,000 \mathrm{DMg}_{\text {day }}{ }^{-1}$ and found a biorefinery in Kerr County with a capacity of 1,074 DMg day ${ }^{-1}$. This biorefinery would be supplied with biomass from Kerr, Bandera, Real, Kimble, Gillespie, Kendall, Bexar, Medina, Edwards, Mason and Uvalde County. Note that in our algorithm, biorefineries are found before depots. Hence, when we adjusted the minimum capacity constraint and found a biorefinery in Kerrr County, a depot was no longer found in Kendall County since the biomass would be destined for Kerr's biorefinery. Figure 6 (a) illustrates how the market radius of a biorefinery in Kerr County and a depot in Kendall County would overlap. The rail system does not traverse Kerr County, hence, no biorefinery would be located in Kerr County with a capacity bound of 1,074 DMg day $^{-1}$. In fact, under the transportation constraint, a third biorefinery would only be found if the capacity bound was lowered to $758 \mathrm{DMg}$ day $^{-1}$. This third biorefinery would be located in Hemphill County. Note that the 2,000 DMg day ${ }^{-1}$ assumed capacity was based on biochemical conversion processes. Thermochemical facilities may have a different optimal size, which may change the predicted amount of stranded resources and the number and geographical distribution of all facilities.

< Fig. 6>

Our raster based heuristic did not make any assumptions of where the location of biomass would be other than the suitable lands. However, we recognize that the economic draw of a biorefinery could pull the biomass production into portions of a county closest to that facility. If we were to consider that the entire all25 scenario potential biomass for each county were to be concentrated on suitable land within $81-\mathrm{kms}$ of the Sherman and Castro biorefineries, an increase of $8 \%$ and $6 \%$ in biomass available would be observed respectively.

Considering all of the biomass in counties within 32-kms from the Kendall and Ochiltree depots found under the all25 scenario increases the total biomass available in the depots by $45 \%$ and $101 \%$ respectively. The high increase in available biomass can be explained with Figures 6 (a) and 6(b). As per Figure 6(a), the counties that would supply the depot in Kendall County have a much higher area than the area of the supply circle. Hence, not all of the biomass in these counties is economically available. Hansford 
County is both in the neighborhood of the biorefinery located in Sherman County and in the neighborhood of the depot located in Ochiltree County, which explains the high increase of available biomass mentioned before (101\%) (Fig. 6(b)). The raster-based heuristic used here ensures that biomass is not double counted when locating facilities. Sherman County borders the state of Oklahoma, and could potentially collect biomass from beyond Texas borders. For the initial analysis, biomass sources were limited to Texas. In a study without these border limits, that biorefinery could collect more biomass. This analysis is discussed later in the paper.

To compare our raster-based heuristic with the conventional method of using county centroids as supply points and potential facilities, we set Texas county centroids to the values in the all25 biomass inventory and found biorefineries and depots. Similar to the results found from our raster-based heuristic, two biorefineries and two depots were located: one biorefinery each in Sherman and Castro Counties, and one depot each in Ochiltree and Kendall Counties. Using the centroids as supply points and potential facilities led to an increase of $7 \%$ in total biomass captured by all facilities in Texas when compared to our raster-based heuristic. An overestimation of total biomass captured would mislead investors in their risk analysis for a sustainable supply. Due to time constraints, we did not apply the county centroid approach nationwide, hence we were not able to quantify the difference between the county centroid approach and the raster approach on a nationwide basis. But, we expect that in regions with more uniformly distributed biomass, the gap between approaches will be lower than $7 \%$.

The GIS-based heuristic to address the capacitated facility location problem presented here was expanded to evaluate the national feedstock SCh. We used the inventories of the past100 and all25 scenarios to evaluate the structure of the likely biomass feedstock SCh that will develop nationwide. Under the all25 scenario, we found a total of 77 biorefineries with capacities greater than 2,000 $\mathrm{Mg}$ day $^{-1}$ and 171 depots with capacities greater than $240 \mathrm{Mg} \mathrm{day}^{-1}$ (Fig. 7). Of the total available biomass, $78 \%$ could be accessed by biorefineries and an additional $12 \%$ by depots, leaving $10 \%$ as stranded biomass. A total of 161 million $\mathrm{Mg}$ year $^{-1}$ of feedstock delivered to biorefineries around the US and 22.7 million $\mathrm{Mg}_{\text {year }}{ }^{-1}$ of feedstock delivered 
to depots. This translates to 65.3 billion liters of advanced biofuels, more than the targeted 60 billion liters of advanced cellulosic biofuel in the RFS2.

Figure 7 maps all the biorefineries and depots found in the US. The five largest biorefineries were found in: McLean County, IL (8,738,123 DMg year $\left.{ }^{-1}\right)$, Lee County, IL (6,902,892 DMg year ${ }^{-1}$ ), White County, IN (5,771,593 DMg year $\left.{ }^{-1}\right)$, Macoupin, IL (5,172,079 DMg year $\left.{ }^{-1}\right)$ and Hamilton, IA (4,983,288 DMg year $\left.{ }^{-1}\right)$. The nationwide analysis, when compared to the analysis solely within Texas, lead to a $25 \%$ increase in biomass accessed by biorefineries and depots located in Texas $\left(3,355,552 \mathrm{DMg}_{\mathrm{gear}}{ }^{-1}-\mathrm{Table}_{-}-\mathrm{as}\right.$ opposed to 2,957,337 accessible biomass-Table 3). This discrepancy is explained by the ability of the rasterbased heuristic to locate facilities regardless of political boundaries. When considering the biomass available nationwide, the location of the biorefinery found in Sherman County, TX shifted $28 \mathrm{~km}$ northeast to capture biomass in the state of Oklahoma. As a result, available biomass in Dallam County was removed from the Sherman County market radius. In combination with nearby counties, there was sufficient biomass to locate a third Texas depot in Dallam County (Fig. 7).

< Fig. $7>$

Because the constraint differences between the past100 and all25 scenarios are mainly in the states along the 100th Meridian (Texas, Oklahoma, Kansas, Nebraska, South Dakota and North Dakota), we also applied the raster based heuristic to the past100 scenario to identify accessible biomass (Table 4). Texas was the state most impacted by the difference by the land use change assumptions between the two scenarios, with a decrease of $39 \%$ in total accessible biomass. The small increase observed in total accessible biomass in Nebraska is explained by a depot found in Rawlins County, Kansas with the past100 inventory, but under all25 estimates, the depot shifts to Hitchcock County, Nebraska.

$<$ Table $4>$

A raster approach, as opposed to a network approach, allows for the analysis of continuous resource surfaces. Hence, the approach used this study eliminated county and state boundaries for biomass resource delivery to a conversion or preprocessing facility. When focal statistics were applied, the pixel values were 
changed based on the neighboring values, regardless of political boundaries. That was in contrast to the previous studies that constrained the collection radius for a location to just one county or state. Our approach also took into consideration geographical data for the existing road and rail systems. Furthermore, the sequence of locating facilities with the algorithm will most likely resemble the progression of the cellulosic industry development (i.e. locations with the greatest available biomass will have facilities first).

The total stranded biomass in Texas was between 16-28\% of the total available biomass, depending on the biomass inventory and/or political boundary considered. The addition of the transportation network accessibility (rail and appropriate roads) in the biofuels industry increased the total stranded biomass in Texas from $28 \%$ to $33 \%$ under the all 25 scenario. An increase of $25 \%$ in total accessible biomass for Texas based facilities was observed when the counties from adjacent states were allowed to provide feedstocks as opposed to limiting the analysis to only Texas counties. We estimated that total nationwide accessible biomass was $90 \%$ of the available biomass when delivered to biorefineries (77 locations accepting $78 \%$ of biomass) and depots (171 depots accepting $12 \%$ of biomass).

\section{Conclusions}

While addressing the capacitated facility location problem for biorefineries and depots using the raster approach presented here does take additional computing time and effort compared to assuming locations at county centroids, several advantages were found to justify the use of the geographic data provided by the National Land Cover Data. Assigning all biomass to county centroids as opposed to distributing that biomass across appropriate land areas results in an increase of $7 \%$ in total biomass estimated to be captured by all facilities in Texas, an overestimation that would affect sustainability policies and planning. The discrepancy in biomass estimations between the two different approaches may be a result of the average county size in Texas $\left(2,699 \mathrm{~km}^{2}\right)$ in combination with the assumed biorefinery and depot market radius $\left(20,612\right.$ and $\left.6,217 \mathrm{~km}^{2}\right)$ and/or the heterogeneous geography of the state. 
Future research could include analyzing different alternative market radius constraints or varying minimum economic sizes for biorefineries and depots, and evaluating the impact on facility location when replacing the total biomass per county with total energy content per county. Additionally, an interesting approach would be to use the same algorithm to evaluate a system that will deliver all available biomass from farms to depots and optimize the location of biorefineries with mixed-integer programming while considering each depot as a supplier to a potential biorefinery.

\section{Acknowledgements}

We acknowledge the USDA Agriculture and Food Research Initiative grant No. 2013-67021-21160, the Oak Ridge National Laboratory and Texas A\&M AgriLife Research for their support of this work. 


\section{References}

[1] S. Fales, J. R. Hess, W. W. Wilhelm, D. Erbach, W. D. Provine, K. P. Vogel, T. A. Peterson, E. C. A. Runge. Convergence of agriculture and energy: II. Producing cellulosic biomass for biofuels (CAST Commentary QTA2007-2). The Council for Agricultural Science and Technology, 291 (2007), pp. 1-8.

[2] J. R. Hess, C. T. Wright, K. L. Kenney. Cellulosic biomass feedstocks and logistics for ethanol production. Bio-fuels Bio-prod Biorefin, 1 (2007), pp. 181-190.

[3] C. N. Hamelinck, G. Van Hooijdonk, A. P. Faaij. Ethanol from lignocellulosic biomass: techno-economic performance in short-, middle-and long-term. Biomass Bioenerg, 28(4) (2005), pp. 384-410.

[4] A. Kumar, S. Sokhansanj. Switchgrass (Pacinum virgatum, L.) delivery to a biorefinery using integrated biomass supply analysis and logistics (IBSAL) model. Bioresour. Technol, 98 (5) (2007), pp. 1033-1044

[5] A. Aden, M. Ruth, K. Ibsen, J. Jechura, K. Neeves, J. Sheehan, B. Wallace. Lignocellulosic Biomass to Ethanol Process Design and Economics Utilizing Co-Current Dilute Acid Prehydrolysis and Enzymatic Hydrolysis for Corn Stover. NREL/TP-510-32438. (2002).

[6] C. Riley, D. Schell. Technical and economic analysis of an enzymatic hydrolysis based ethanol plant. Solar Energy Research Institute Internal Report. Golden, CO. (1991).

[7] S. Sokhansanj, A. Turhollow, J. Cushman, J. Cundiff. Engineering aspects of collecting corn stover for bioenergy. Biomass Bioenerg, 23(5) (2002), pp. 347-355.

[8] J. R. Hess, C. T. Wright, K. L. Kenney, K. L., E. M. Searcy. Uniform-format solid feedstock supply system: a commodity-scale design to produce an infrastructure-compatible bulk solid from lignocellulosic biomass-executive summary. INL/EXT-09-15423. (2009).

[9] J. E. Carolan, S. V. Joshi, B. E. Dale. Technical and financial feasibility analysis of distributed bioprocessing using regional biomass pre-processing centers. J. of Agr Food Ind Organ, 5(2) (2007), pp. $1-27$.

[10] A. M. Argo, E. C. Tan, D. Inman, M. H. Langholtz, L. M. Eaton, J. J. Jacobson, C. T. Wright, D. Muth, M. M. Wu, Y. W. Chiu, R. L. Graham. Investigation of biochemical biorefinery sizing and environmental sustainability impacts for conventional bale system and advanced uniform biomass logistics designs. Biofuels Bioprod Biorefin, 7(3) (2013), pp. 282-302.

[11] R. D. Perlack, L. M. Eaton, A. F. Turhollow Jr., M. H. Langholtz, C. C. Brandt, M. E. Downing, R. L. Graham, L. L. Wright, J. M. Kavkewitz, A. M. Shamey. US billion-ton update: biomass supply for a bioenergy and bioproducts industry. ORNL/TM-2011/224. Oak Ridge National Laboratory, Oak Ridge, TN. (2011).

[12] D. S. Gonzales, S. W. Searcy, L. M. Eaton. Assessment of the Predicted Biomass Production in the Billion Study Update. Paper from the Annual International Meeting. American Society of Agricultural Engineers. 152181831 (2015).

[13] C.G. Homer, J.A. Dewitz, L. Yang, S. Jin, P. Danielson, G. Xian, J. Coulston, N. D. Herold, J. D. Wickham, K. Megown. Completion of the 2011 national land cover database for the counterminous United States. Photogramm. Eng. Remote Sens, 81(5) (2015), pp. 345-354

[14] J. Jacobson, K. Cafferty, M. Roni, P. Lamers, K. Kenney. Feedstock and Conversion Supply System Design and Analysis-The Feedstock Logistics Design Case. INL/EXT-14-33227. Idaho National Laboratory, Idaho Falls, ID. (2014).

[15] P. Lamers, E. C. D. Tan, E. M. Searcy, C. J. Scarlata, K. G. Cafferty, J. J. Jacobson. Techno-economic analysis of decentralized biomass processing depots. Bioresour Technol, 194 (2015), pp. 205-213.

[16] P. McKendry. Energy production from biomass (part 1): overview of biomass. Bioresour Technology, 83(1) (2002), pp. 37-46.

[17] R. Zamora-Cristales, K. Boston, J. Sessions, G. Murphy. Stochastic simulation and optimization of mobile chipping economics in processing and transport of forest biomass from residues. Silva Fennica, 47(5) (2013), pp. 1-22.

[18] M. S. Roni, S. D. Eksioglu, E. Searcy, K. Jha. A supply chain network design model for biomass cofiring in coal-fired power plants. Transp. Res. Part E: Logist. Transport. Rev. 61 (2014), pp. 115-134.

[19] D. Muth, J. Jacobson, K. Cafferty, R. Jeffers. Define feedstock baseline scenario and assumptions for the \$80/DT target based on INL design report and feedstock logistics projects. INL/EXT-14-31569. Idaho National Laboratory, Idaho Falls, ID. (2013). 
[20] C. Wright, K. Kenney, J. Jacobson. Integrated model analysis using field-and PDU-scale data to demonstrate feedstock logistics cost of $\$ 35.00$ per dry ton for corn stover. TM2012-003-0 STIMS INL/MIS-13-28680. Idaho National Laboratory, Idaho Falls, ID. (2012).

[21] M. Kaylen, D. L. Van Dyne, Y-S. Choi, M. Blasé. Economic feasibility of producing ethanol from lignocellulosic feedstocks. Bioresour Technol, 72(1) (2000), pp. 19-32.

[22] M. Wright, R.C. Brown. Establishing the optimal sizes of different kinds of biorefineries. Biofuel Bioprod Bior, 1 (3) (2007), pp. 191-207.

[23] J. Leboreiro, A. K. Hilaly. Biomass transportation model and optimum plant size for the production of ethanol. Bioresour Technol, 102(3) (2011), pp. 2712-2723.

[24] P. Lamers, E. C. D. Tan, E. M. Searcy, C. J. Scarlata, K. G. Cafferty, J. J. Jacobson. Strategic supply system design-a holistic evaluation of operational and production cost for a biorefinery supply chain. Biofuels Bioprod Biorefin, 9(6) (2015), pp. 648-660.

[25] D. J. Muth, M. H. Langholtz, E. C. D. Tan, J. J. Jacobson, A. Schwab, M. M. Wu, A. Argo, C. C. Brandt, K. G. Cafferty, Y. Chiu, A. Dutta, L. M. Eaton, E. M. Searcy. Investigation of thermochemical biorefinery sizing and environmental sustainability impacts for conventional supply system and distributed pre-processing supply system designs. Biofuels Bioprod Biorefin, 8(4) (2014), pp. 545-567.

[26] DOE US. Multi-year program plan. Washington, DC: U.S. Department of Energy. (2015). Available from: http://www.energy.gov/sites/prod/files/2015/03/f20/mypp_beto_march2015.pdf. Last accessed August $16^{\text {th }}$.

[27] A. M. Acharya, D. S. Gonzales, S. D. Eksioglu, S. Arora. An Excel-Based Decision Support System for Supply Chain Design and Management of Biofuels. International J Operations Res. Inf. Syst (IJORIS), 5(4) (2014), pp. 26-43.

[28] S. D. Ekşioğlu, A. Acharya, L. E. Leightley, S. Arora. Analyzing the design and management of biomassto-biorefinery supply chain. Comput \& Industrial Eng, 57(4) (2009), pp. 1342-1352.

[29]E. Weisstein. NP-Hard Problem. MathWorld-A Wolfram Web Resource. (2015). Available from: http://mathworld.wolfram.com/NP-HardProblem.html. Last Accessed August 16 ${ }^{\text {th }}, 2015$.

[30]E. Weisstein. NP-Problem. MathWorld-A Wolfram Web Resource. (2015). Available from: http://mathworld.wolfram.com/NP-Problem.html. Last Accessed August 16 $6^{\text {th }}, 2015$.

[31] M. Charikar, S. Guha. Improved combinatorial algorithms for the facility location and k-median problems. Proceedings of the 40th Annual Symposium on Foundations of Computer Science. (October 1999), pp.378.

[32] M. Charikar, S. Guha, É. Tardos, D. B. Shmoys. A constant-factor approximation algorithm for the kmedian problem (extended abstract). Proceedings of the thirty-first annual ACM symposium on Theory of computing. Atlanta, Georgia, USA. (May 1999), pp.1-10.

[33] D. Erlenkotter. A dual-based procedure for uncapacitated facility location. Operations Res. 26(6) (1978), pp. 992-1009.

[34] S. Guha, S. Khuller. Greedy strikes back: improved facility location algorithms. Proceedings of the ninth annual ACM-SIAM symposium on discrete algorithms. San Francisco, California, USA. (January 1998), pp.649-657.

[35] D. S. Hochbaum. Heuristics for the fixed cost median problem. Math Program, 22(1) (1982), pp. 148162.

[36] K. Jain, M. Mahdian, A. Saberi. A new greedy approach for facility location problems. Proceedings of the thirty-fourth annual ACM symposium on Theory of computing. DOI:10.1145/509907.510012. Montreal, Quebec, Canada. (May 2002).

[37] K. Jain, V. V. Vazirani. Approximation algorithms for metric facility location and k-Median problems using the primal-dual schema and Lagrangian relaxation. J of the ACM (JACM), 48(2) (2001), pp. 274296.

[38] A. A. Kuehn, M. J. Hamburger. A heuristic program for locating warehouses. Manag Sci, 9(4) (1963), pp. 643-666.

[39] J.-H. Lin, J. S. Vitter. Approximation algorithms for geometric median problems. Information Processing Letters, 44(5) (1992), pp. 245-249.

[40] R. M. Nauss. An improved algorithm for the capacitated facility location problem. J of the Operational Research Soc, 29(12) (1978), pp. 1195-1201 
[41]D. B. Shmoys, É. Tardos, K. Aardal. Approximation algorithms for facility location problems (extended abstract). Proceedings of the twenty-ninth annual ACM symposium on Theory of computing. El Paso, TX. (1997), pp.265-274

[42] C. E. Noon, M. J. Daly. GIS-based biomass resource assessment with BRAVO. Biomass Bioenerg, 10(2) (1996), pp.101-109.

[43] R. Graham, W. Liu, M. Downing, C. Noon, M. Daly, A. Moore. The effect of location and facility demand on the marginal cost of delivered wood chips from energy crops: a case study of the state of Tennessee. Biomass Bioenerg, 13(3) (1997), pp. 117-123.

[44] R. L. Graham, B. C. English, C. E. Noon. A geographic information system-based modeling system for evaluating the cost of delivered energy crop feedstock. Biomass Bioenerg, (2000) 18(4), pp. 309-329.

[45] W. Liu, R. A. Merriam, V. D. Phillips, D. Singh. Estimating short-rotation Eucalyptus saligna production in Hawaii: An integrated yield and economic model. Bioresour Technology, 45(3) (1993), pp.167-176.

[46] W. Liu, V. D. Phillips, D. Singh. A spatial model for the economic evaluation of biomass production systems. Biomass Bioenerg, 3(5) (1992), pp. 345-356.

[47] V. D. Phillips, W. Liu, R. A. Merriam, D. Singh. Biomass system model estimates of short-rotation hardwood production in Hawaii. Biomass Bioenerg, 5(6) (1993), pp. 421-429.

[48] L. Panichelli, E. Gnansounou. GIS-based approach for defining bioenergy facilities location: A case study in Northern Spain based on marginal delivery costs and resources competition between facilities Biomass Bioenerg, 32 (4) (2008), pp. 289-300.

[49] J. Ranney, J. Cushman. Regional evaluation of woody biomass production for fuels in the southeast. Biotechnology and Bioengineering Symposium No. 10, Wiley, New York. (1980), pp. 109-120.

[50] W. A. Marvin, L. D. Schmidt, S. Benjaafar, D. G. Tiffany, P. Daoutidis. Economic optimization of a lignocellulosic biomass-to-ethanol supply chain. Chem Eng Sci, 67(1) (2012), pp. 68-79.

[51]D. R. Petrolia. The economics of harvesting and transporting corn stover for conversion to fuel ethanol: A case study for Minnesota. Biomass Bioenerg, 32(7) (2008), pp. 603-612.

[52] USDA NASS. Agric. Statistics Data Base (Quick Stats). (2015). Available from: http://quickstats.nass.usda.gov/. Last Accessed January 15, 2016.

[53] USDA NASS. Cropland Data Layer: Published crop-specific data layer. USDA-NASS, Washington, DC. (2014). Available at https://nassgeodata.gmu.edu/CropScape/. Last accessed August $16^{\text {th }}$.

[54]DOE U.S. Biomass multi-year program plan. United States Department of Energy, Energy Efficiency \& Renewable Energy, Office of Biomass Program. Washington, DC. (2011).

[55] TNRIS. Texas Natural Resources Information System: Texas statewide imagery and GIS data: Transportation. (2013). Available from: https://tnris.org/maps-and-data/. Last Accessed August $16^{\text {th }}$, 2015. 
Fig. 1 Biomass feedstock supply chain for biorefineries and depots

Fig. 2 Lands identified as suitable for lignocellulosic biomass from the 2011 NLCD [13]

Fig. 3 Representation of yields assigned to each county on suitable lands and the market radius of the biorefinery found in Castro County under the all25 scenario

Fig. 4 Pseudo-code for the algorithm to locate biorefineries with a minimum capacity of 2,000 DMg day $^{-1}$ with the option for considering the transportation infrastructure (grey text)

Fig. 5 Biorefineries (large blue circles) and depots (small green circles) found under different production level assumptions in Texas.

Fig. 6 (a) Supply radius overlap of potential biorefinery and depot when relaxing the minimum biorefinery capacity constraint. The heuristic algorithm locates either the biorefinery or the depot. (b) Supply radius intersection between Sherman's biorefinery and Ochiltree's depot.

Fig. 7 Map of biorefineries and depots found in the US using the all25 biomass inventory 


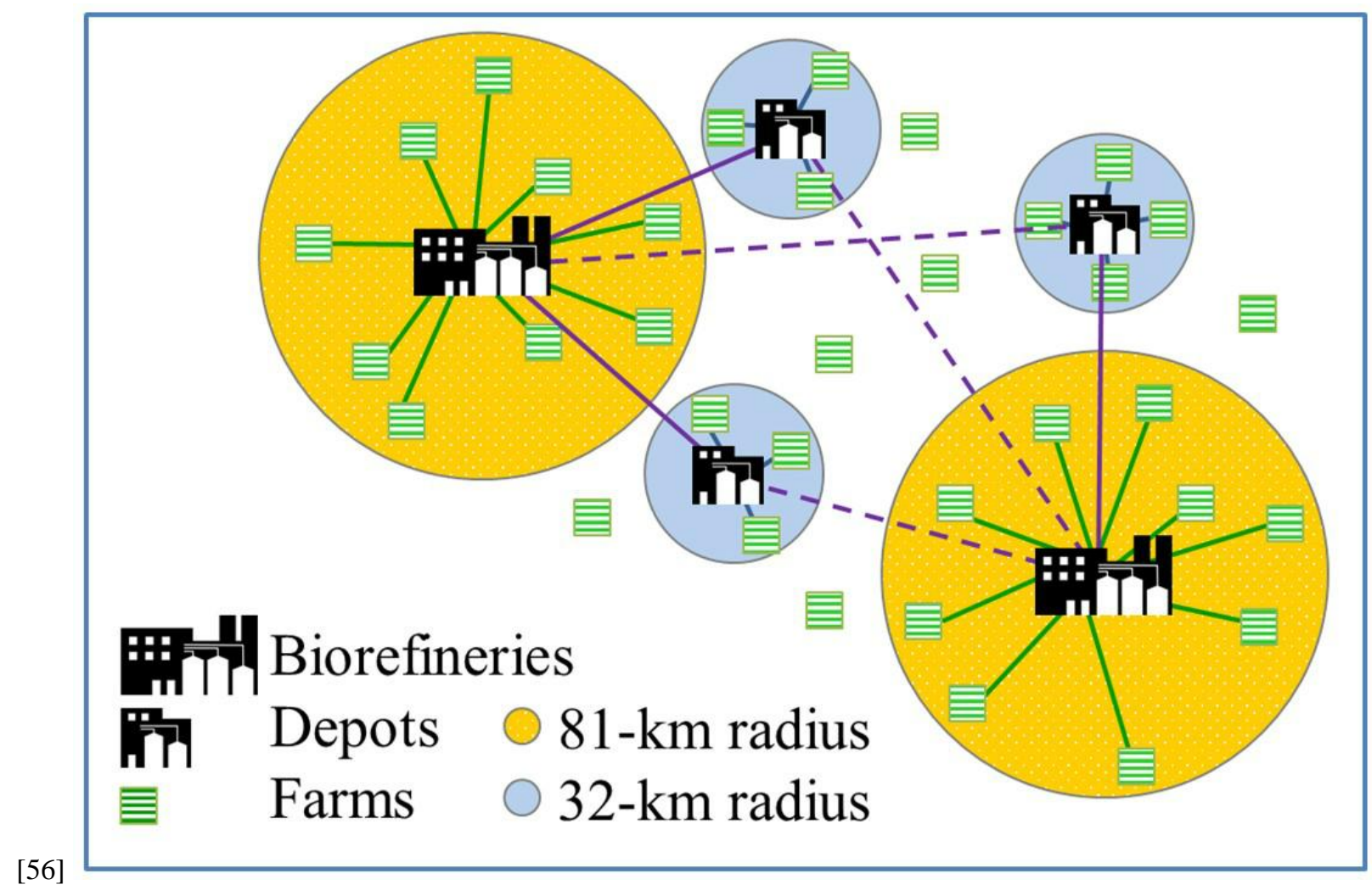




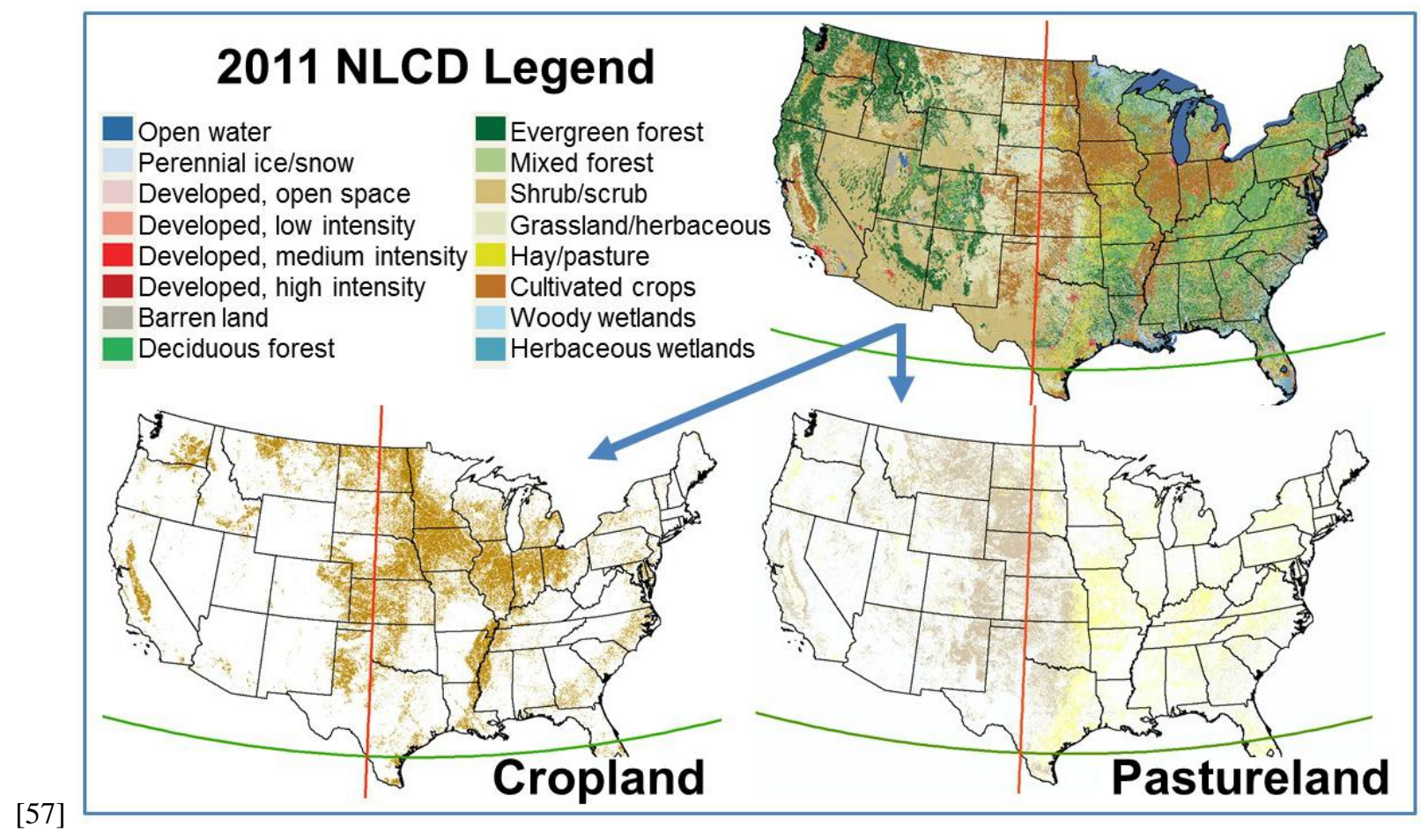




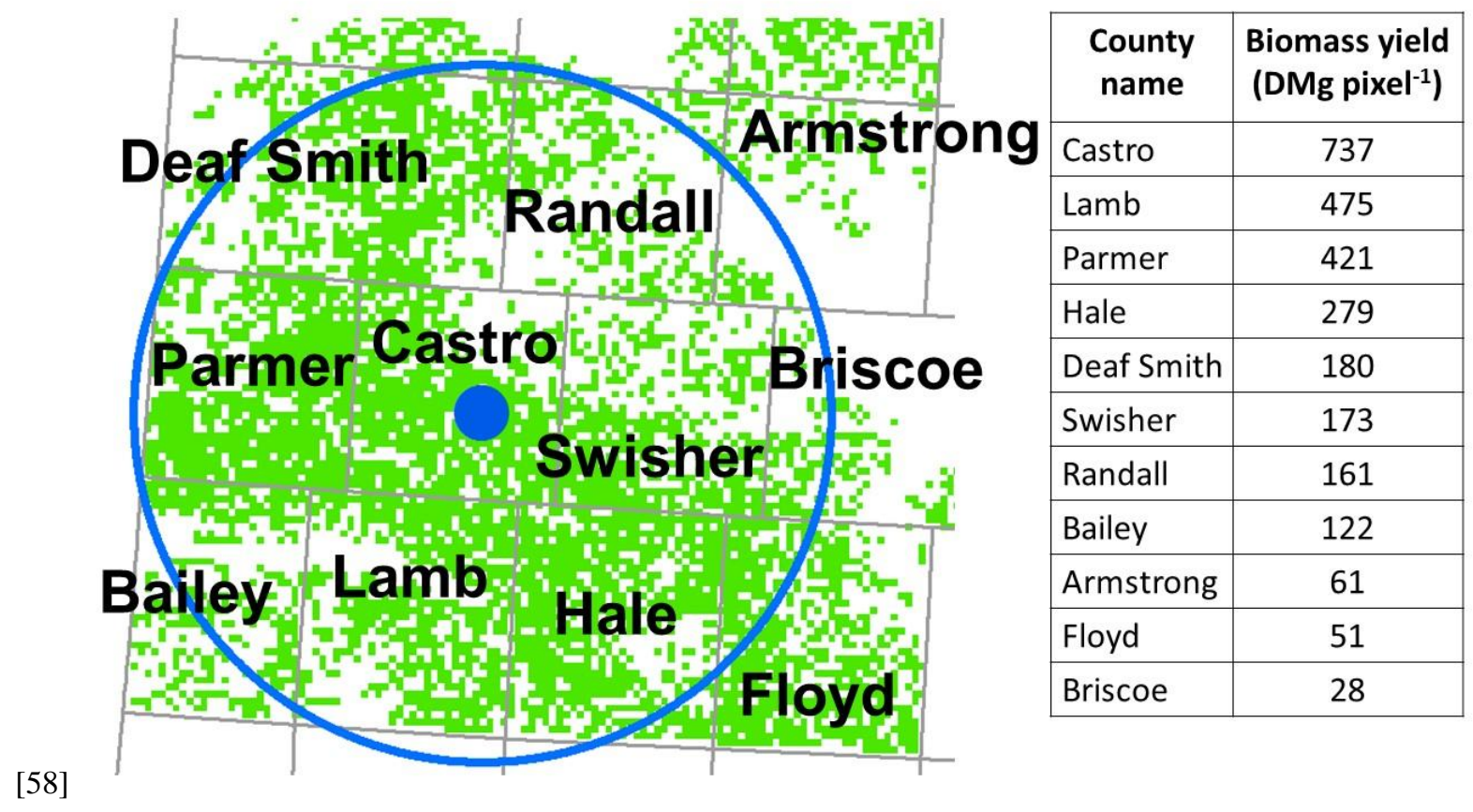


$x=0$

Do While cell values $<>0$

$x=x+1$

Focal statistics (Input: Biomass $(x)$ Radius: $81 \mathrm{~km}$ Output: BiomassCumulative $(x)$ )

Intersection (Input: BiomassCumulative $(x) \cap$ Road $\cap$ Rail Output: BiomassCumulative $(x)$ )

If highest cell value in BiomassCumulative ${ }_{(x)} \geq 2,000 \mathrm{DMg}$ Then

Locate Biorefinery $(x)$

Set Cell values $81 \mathrm{~km}$ radius of Biorefinery $(x)=$ zero (Input: Biomass $(x)$ Output:

Biomass $(x+1))$

End If

[59]

Loop 


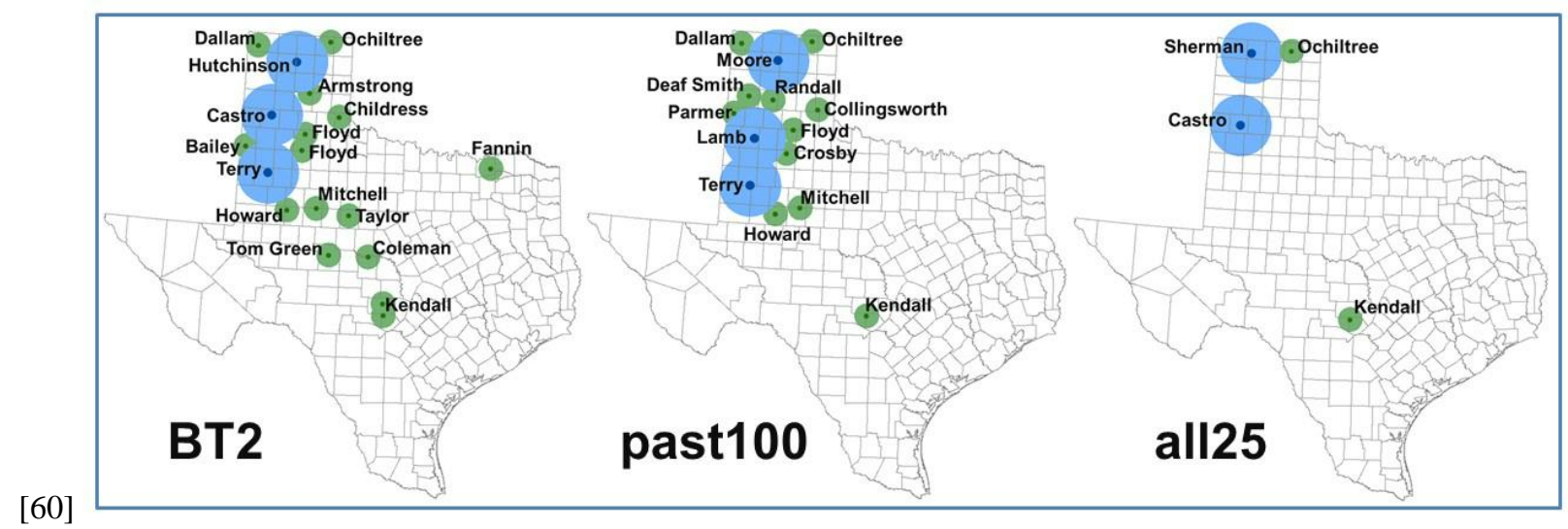




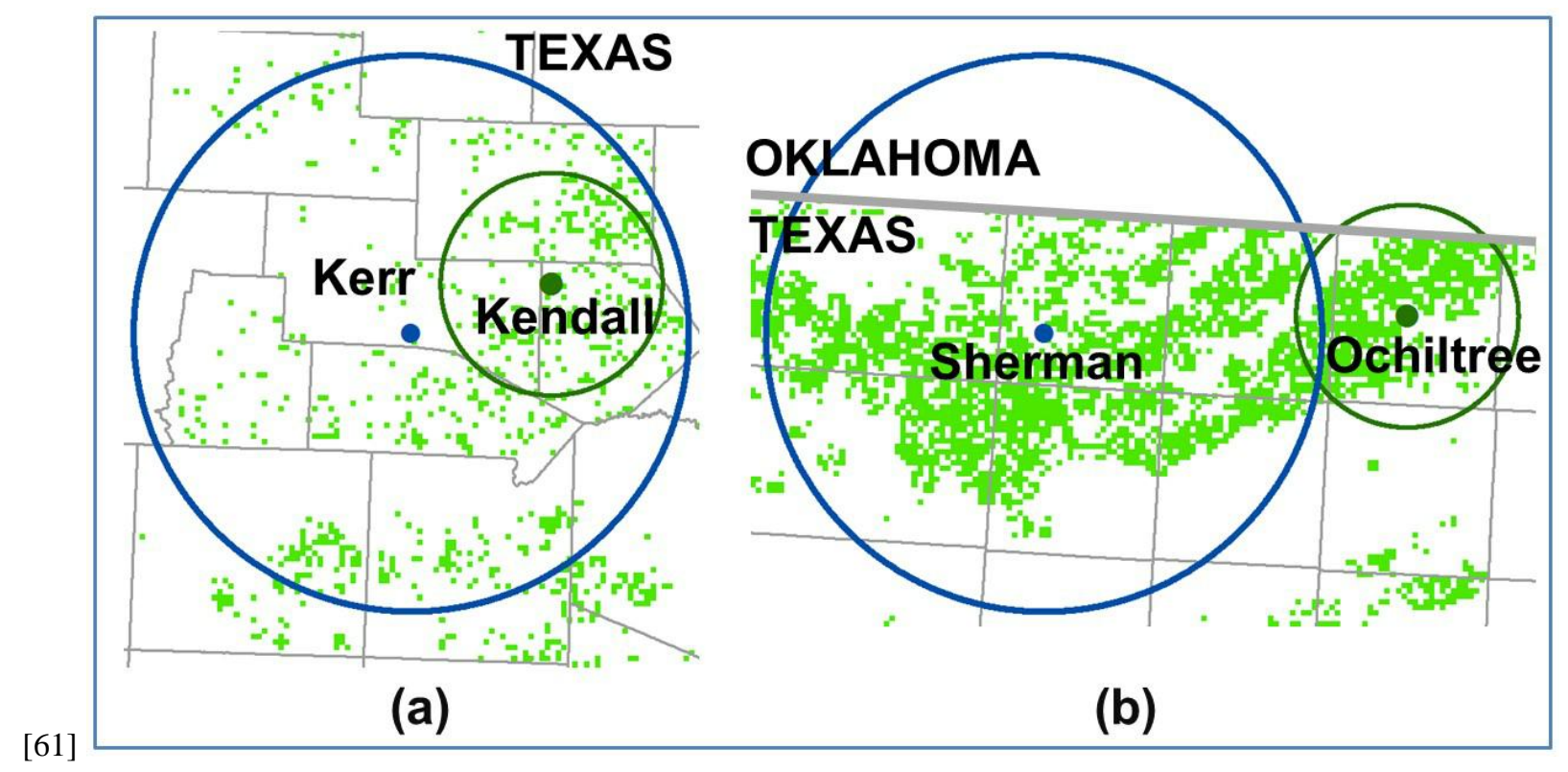




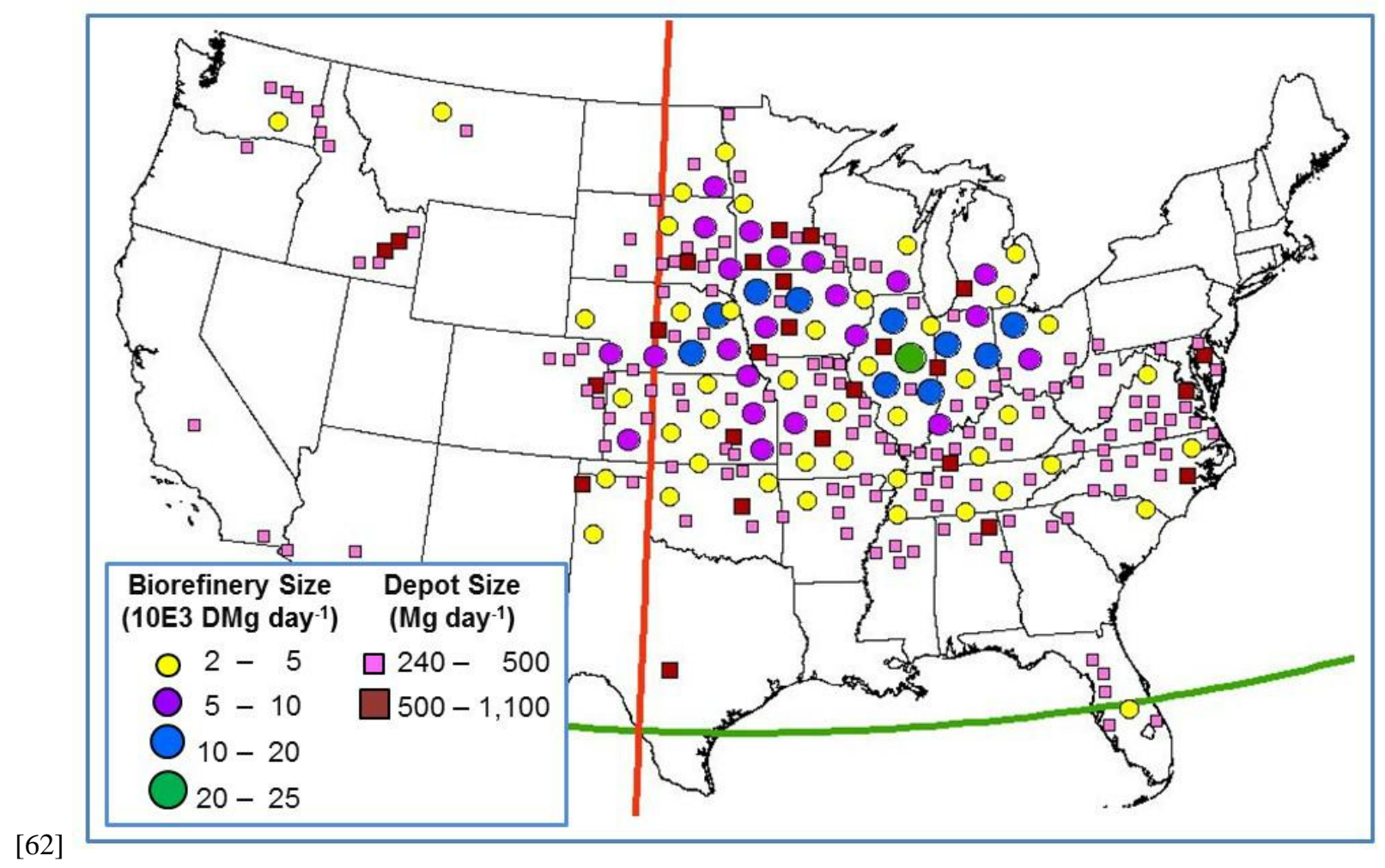


Table 1. NLCD suitable land classifications for assignment to biomass types Cropland Pastureland

\begin{tabular}{ll}
\hline - Crop residues (barley, corn, oats, & - Perennial grass established on \\
sorghum, wheat) & cropland used as pasture \\
- Annual energy crops & - Perennial grass established on \\
- Perennial grass established on & permanent pasture \\
cropland &
\end{tabular}
cropland 
Table 2. Available biomass in Texas based on different production level assumptions Scenario County

\begin{tabular}{llc}
\hline \multicolumn{1}{c}{ Scenario } & \multicolumn{1}{c}{ County } & Capacity (DMg year ${ }^{-1}$ ) \\
\hline \multirow{4}{*}{ BT2 } & Terry biorefinery & $1,773,919$ \\
\cline { 2 - 3 } & Castro biorefinery & $1,550,684$ \\
\cline { 2 - 3 } & Hutchinson biorefinery & $1,376,335$ \\
\cline { 2 - 3 } & 15 depots & $2,326,296$ \\
\cline { 2 - 3 } & Accessible biomass & $7,027,234$ \\
\cline { 2 - 3 } & Stranded biomass & $1,500,370$ \\
\hline \multirow{5}{*}{ past100 } & Lamb biorefinery & $1,795,173$ \\
\cline { 2 - 3 } & Moore biorefinery & $1,340,766$ \\
\cline { 2 - 3 } & Terry biorefinery & 754,338 \\
\cline { 2 - 3 } & 10 depots & $1,264,555$ \\
\cline { 2 - 3 } all25 & Accessible biomass & $5,154,832$ \\
\cline { 2 - 3 } & Stranded biomass & $1,329,642$ \\
\hline & Sherman biorefinery & $1,300,233$ \\
\cline { 2 - 3 } & Castro biorefinery & $1,240,044$ \\
\cline { 2 - 3 } & 2 depots & 417,061 \\
\cline { 2 - 3 } & Accessible biomass & $1,151,389$ \\
\cline { 2 - 3 } & Stranded biomass & \\
\hline
\end{tabular}


Table 3. Available biomass in Texas under the all25 scenario based on proximity to the transportation infrastructure Without the Transportation Network Boundary

\begin{tabular}{lclc}
\hline Facility & Capacity (DMg year ${ }^{-1}$ ) & & Capacity (DMg year $^{-1}$ ) \\
\hline Sherman biorefinery & $1,300,233$ & Sherman biorefinery & $1,299,744$ \\
\hline Castro biorefinery & $1,240,044$ & Castro biorefinery & $1,239,366$ \\
\hline Ochiltree depot & 226,906 & Ochiltree depot & 220,930 \\
\hline Kendall depot & 190,155 & & $\mathbf{2 , 7 6 0 , 0 4 0}$ \\
\hline Accessible biomass & $\mathbf{2 , 9 5 7 , 3 3 7}$ & Accessible biomass & $\mathbf{1 , 3 4 8 , 6 8 6}$ \\
\hline Stranded biomass & $\mathbf{1 , 1 5 1 , 3 8 9}$ & Stranded biomass & \\
\hline
\end{tabular}


Table 4. Total accessible biomass for the US and states along the 100th Meridian Geographic

\section{Accessible biomass (DMg year ${ }^{-1}$ )}

scope

US

Texas

Oklahoma

Kansas

Nebraska

North Dakota

South Dakota past100 $191,056,588$

$5,473,744$

4,361,368

$16,725,332$

$18,582,173$

$7,949,884$

4,025,649 all25

Percent change

from past100

$183,999,460$

$3,355,552$

$4,180,452$

$15,834,480$

$18,628,928$

$7,879,250$

4,025,649
$-4 \%$

$-39 \%$

$-39 \%$

$-5 \%$

$-5 \%$

$0.3 \%$

$-1 \%$

No change

[63] 